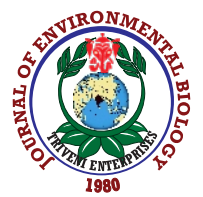

\title{
Study on biology of tea bunch caterpillar Andraca bipunctata on alternative host plant Eurya acuminata of Meghalaya
}

\author{
R. Pande ${ }^{*}$, M. Pitchaimurugan, R.J. Joga, S. Hazarika, S. Patra and G.I. Ramkrushna \\ ICAR Research Complex for NEH Region, Umiam-793 103, India \\ *Corresponding Author Email : rachna.ento@gmail.com
}

\section{Abstract}

Aim: The present study was carried out to study the biology of tea caterpillar Andraca bipunctata on Eurya acuminata as an alternate host which will be useful for tea growers of Meghalaya and nearby area to monitor the incidence and timely management of this pest on alternative host itself.

Methodology: Insect population was collected from Umiam, Ri-Bhoi district situated in the mid altitude hills (Khasi hills) of Meghalaya. Six locations were selected randomly within the locality for the collection of eggs, larval instars and pupae from the host plant. Host plant was identified at Agro-forestry Division, ICAR-Research Complex for $\mathrm{NEH}$, Umiam. Observations on all the biological parameters were recorded under laboratory conditions and analysed accordingly.

Results: In present study, an alternative host of $A$. bipunctata was found in midaltitude hills of Meghalaya state during survey which was identified as Eurya acuminata The insect was able to easily survive and complete its whole life cycle on this host plant, E. acuminata

Interpretation: $E$. acuminate acted as an alternative host and safe reservoir site for all the stages of $A$. bipunctata and thereby this host plant helps to survive the pest during unfavorable condition in main host (tea plantation). A. bipunctata is able to multiply their population on $E$. acuminata and get ready to damage on the main host for successive years.

Key words: Alternative host, Bacillus sp., Bunch caterpillar, Endromidae, Eurya acuminata

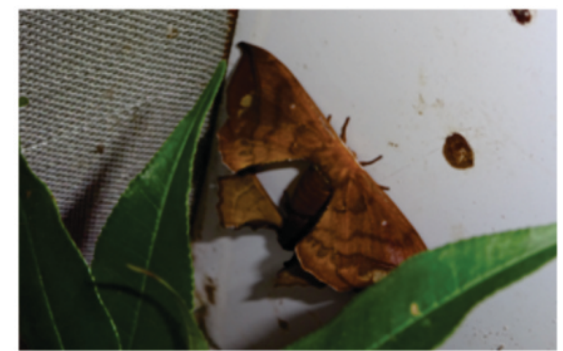

Andraca bipunctata major insect pests of tea



A. bipuncatata cocoon reared on Eurya sp.

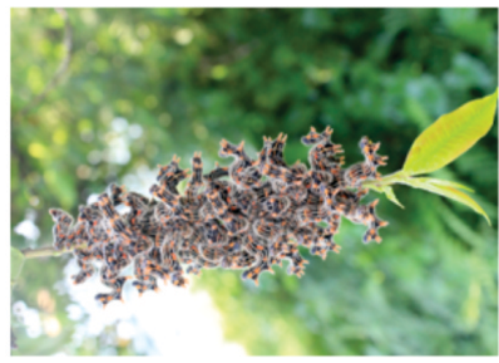

Bunch of caterpillar feeding on Eurya sp.



Eurya sp. as an alternate host gives shelter to A. bipunctata

How to cite : Pande, R., M. Pitchaimurugan, R.J. Joga, S. Hazarika, S. Patra and G.I. Ramkrushna: Study on biology of tea bunch caterpillar Andraca bipunctata on alternative host plant Eurya acuminata of Meghalaya. J. Environ. Biol., 41, 782-787 (2020). 


\section{Introduction}

In India, tea (Camellia sinensis (L.) Kuntze) (family: Theaceae) is the most popular non-alcoholic beverages mainly grown in North-East India. It contributes about $78 \%$ of the total area under tea cultivation, making India the largest tea producer in the world (Soni et al., 2015). It is the main commercial crop of North Eastern region, especially Assam region of India. Tea plantation is a perennial crop, grown as monoculture provides a congenial, perfect and permanent habitat to different fauna (Muraleedharan, 1992; Hazarika et al., 1994, 2001). Tea plant is attacked by several insects on all the parts of the plants viz., root, stem, leaf, flower and seed (Rustagi, 1995; Subramanium, 1995) resulting in 10-25\% loss in terms of yield which may be equivalent to loss of 3 thousand $\mathrm{kg}$ of processed tea/hectare (Subramanium, 1995; Hazarika, et al., 2001). Among the 22 insect pests of tea including mite, sucking pests, leaf eaters and soil-borne pests (Saha and Mukhopadhyaya, 2013), Andraca bipunctata Walker, (Lepidoptera: Endromidae) is the well-known most serious pest and folivores. It is widely distributed in China, Indonesia, Taiwan, Vietnam, Nepal and India (Banerjee, 1983; Chu and Wang, 1996; Panigrahi, 2007, Ghorai et al., 2010; Wang et al., 2012). In India, the pest prevails in Assam, Sikkim, West Bengal, Meghalaya and almost all other districts of North-east India in traces (Banerjee, 1982).

Larvae of $A$. bipunctata feed on the leaves of Camellia sp. commonly known as tea plant/shrub prominently on $C$. sinensis (Chinese variety); C. assamica (Assamese variety) and C. oleifera, which are cultivated tea plant and occasionally on other $C$. japonica and $C$. drupifera in nearby areas all the year round (Ghorai et al., 2010; Wang et al., 2011). Caterpillar of $A$. bipunctata has gregarious feeding habit and hence, are known as 'bunch caterpillar' or 'cluster caterpillar' which causes direct economic loss. This gregarious nature continued upto cocoon formation as 2-4 larvae form a single cocoon (Nath and Rahman, 2012). In a bunch, number of caterpillar varies from 25 to 93 larvae per plant and its 20 larvae can consume $83744.28 \mathrm{mg}$ to $97122.80 \mathrm{mg}$ of leaves per year depends on the season (Ghorai et al., 2010). Even though caterpillars have their own preference to a particular host plant species (Kumata, 1993) but the intensity of damage caused by larvae depends on the generation $\left(1^{\text {st }}\right.$ or $\left.2^{\text {nd }}\right)$ and not on the larval stage and tea variety (Ghorai et al., 2010). Severe damage of $A$. bipunctata may cause abandonment of tea plantation (Banerjee, 1982). Though, adult shows camouflage to the dry leaves (Ghorai et al., 2010) but in nature key mortality factor for all stages of $A$. bipunctata are available which limits the population of Andraca at particular canopy. Presence of an alternative host supplies the safe, untreated food source for survival of population. In present study, bunch caterpillar was found on a tree species in mid-altitude hills of Meghalaya. Biological parameters of $A$. bipunctata were studied on the same host plant to understand the role of plant as an alternative host which may be act as a reservoir of the $A$. bipunctata population and will be responsible for the damage to tea plantation in Assam and adjoining areas.

\section{Materials and Methods}

Insect population was collected from Umiam, Ri-Bhoi district situated in the mid altitude hills (Khasi hills) of Meghalaya, India. Six locations were selected randomly within the locality (nongsder village, pyllun village, mawbri village, area near umroi cantonment, chaar kilo area and area near umiam lake) for the collection of eggs, larval instars, and pupae from the host plant. Host plant was identified at Agro-forestry Division, ICARResearch Complex for NEH, Umiam. Observation on incubation period, hatchability (\%), larval period, pre pupal and pupal period, male and female longevity, fecundity and life period were recorded daily under laboratory conditions. Larvae were reared on natural food (fresh leaves of plant from where larvae were collected) under controlled conditions and moths were supplied with $10 \%$ of honey solution dipped cotton plug every alternate day as sugar source. Moths were then allowed to pair and lay the eggs on twig of host plant (fresh twigs of plant from where larvae were collected). Statistical software SPSS Version 16.0 for windows was used to calculate mean values and SEm (SPSS, 2007).

\section{Results and Discussion}

Bunch of Andraca bipuncttata caterpillars were noticed during survey on a tree plant, Eurya acuminata a dioecious species belonging to the family Theaceae. It is a tropical evergreen tree, commonly known as Diengg-lapyrshit/ Diengpyrshittheh in Khasi hills of Meghalaya (Fig. 1, 2) (Kanjilal et al., 1934-40). The leaves of this plant are used to adulterate tea as it has some pungent aroma. From the agroforestry point of view, this tree has significance as a pioneer species in degraded open areas, forest, woodland as it grow fast, has dense canopy, suppress weeds, and further it attracts birds, bats which act as the seed dispersing agents (Huxley, 1992, Wu et al., 1994-2013). Presence of this alternative host in the adjoining areas of tea estate of Assam can make the tea plantation more vulnerable for the attack of $A$. bipuncttata.

In the present investigation, the bunch caterpillar showed similar developmental durations on $E$. acuminate under laboratory condition as earlier reported on tea Camelia sinensis (Nath and Rahman, 2012). Under laboratory conditions caterpillars of $A$. bipunctata were found feeding on the leaves of E. acuminata in group for $33.20 \pm 0.1$ days (mean $\pm S E M, n=50$ ) (Fig. 3). Before pupation larvae stop feeding and become motionless. Caterpillar preferred to pupate on plant itself and use leaves as a substrate to be adhered (Fig. 4). Sometimes fallen leaves (dry or green on the basis of availability) were preferred for the pupation. Cocoon (pupa) of $A$. bipunctata were brown (reddish to dark) in color and covered with the hairs (Fig.5). 



Fig. 1 : A dioecious tree specie Eurya acuminata (Theaceae).
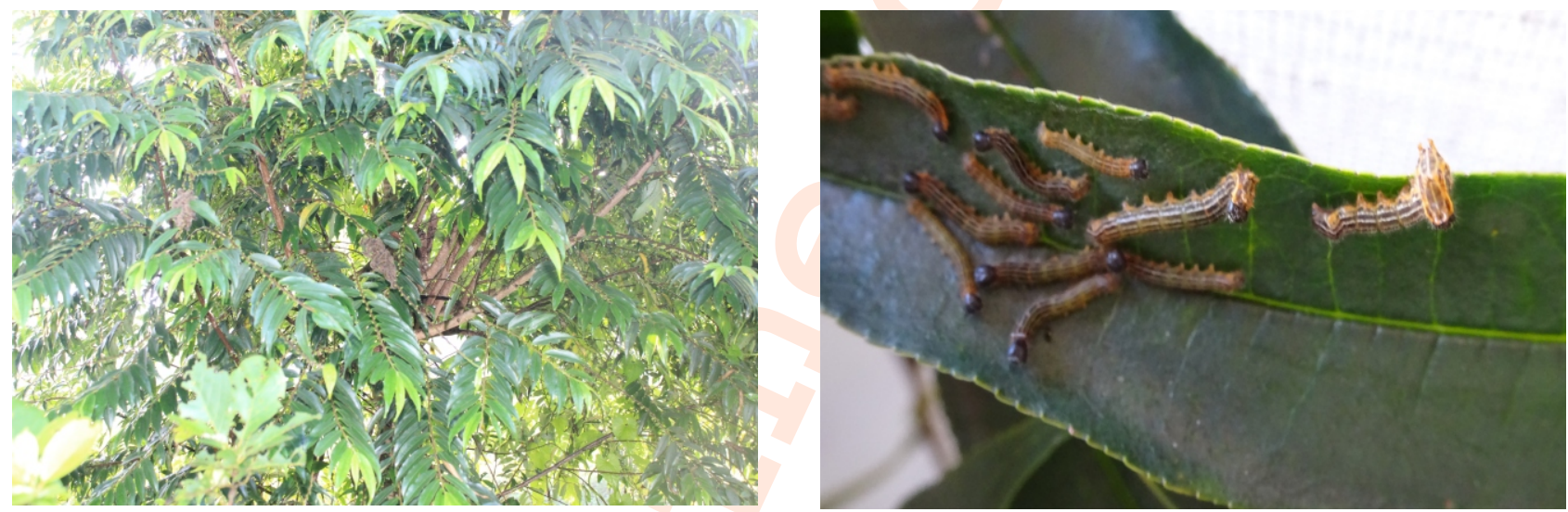

Fig. 2 : Tree of $E$. acuminata infested with bunch caterpillar (Andraca bipunctata).

Fig. 3 : A.bipunctata larvae feeding on leaf of $E$. acuminata.
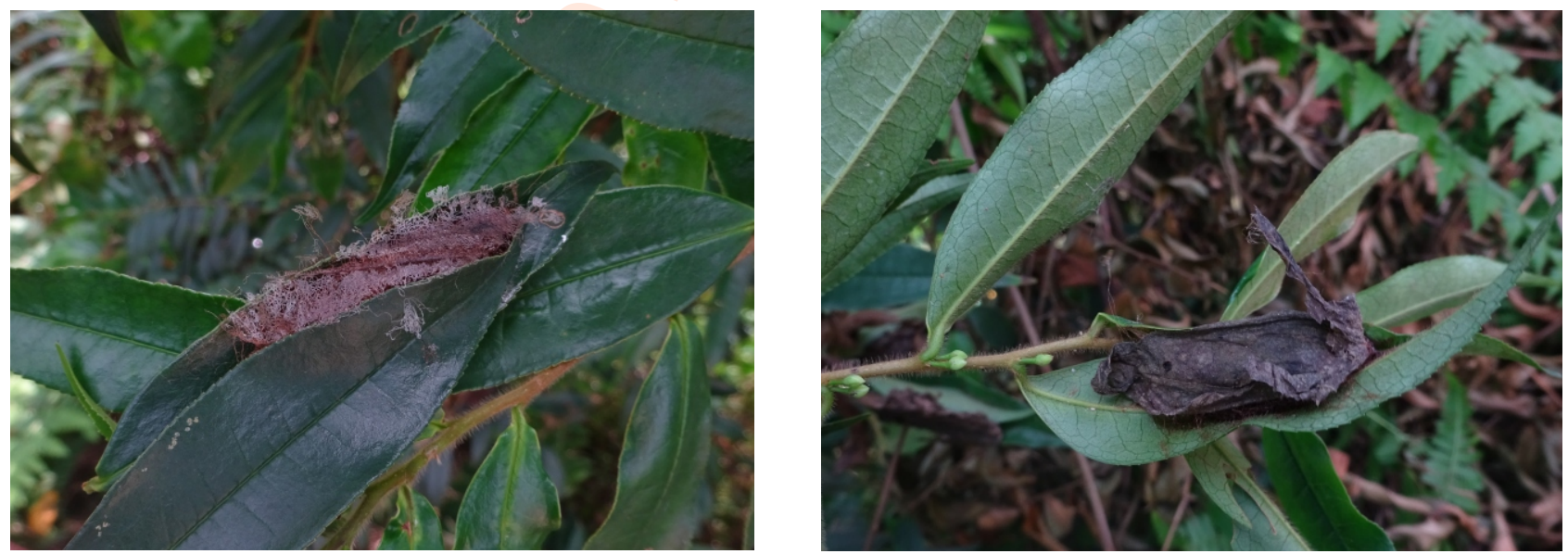

Fig. 4 : Caterpillar pupates on plant itself and use leaves as a substrate to be adhered. 

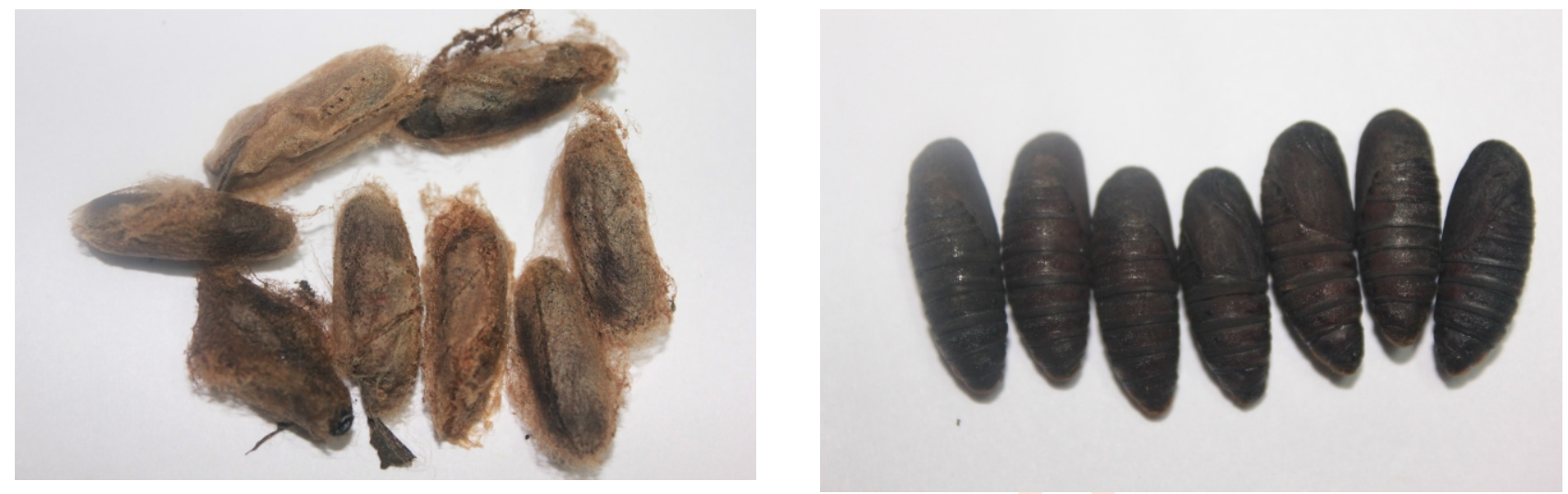

Fig. 5 : Cocoon (pupa) of $A$. bipunctata brown (reddish to dark in color) covered with hairs.



Fig. 6 : End-to- end mating of male and female ( bigger in size ) of $A$. bipunctata.

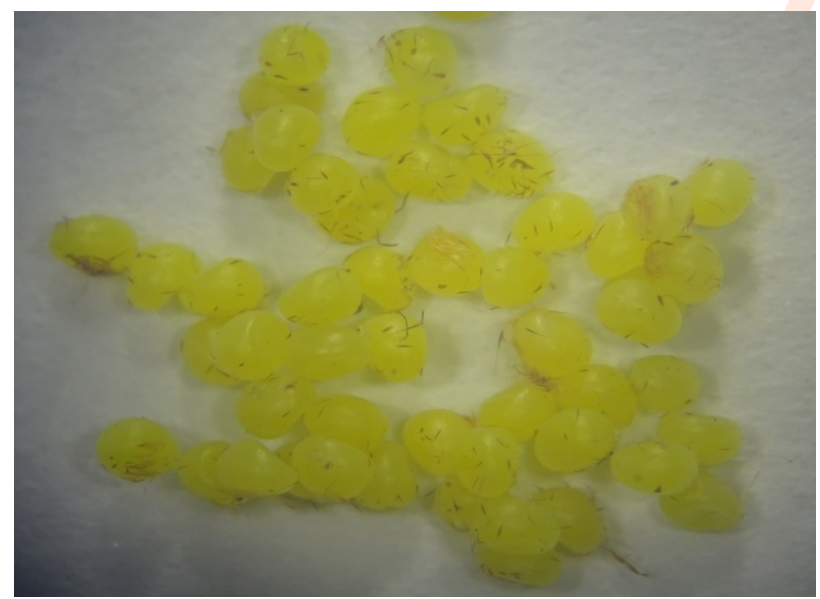

Fig. 8 : Eggs of $A$. bipunctata

During our investigation, it was found that single larvae formed single cocoon unlikely to the previous studies reported by Ghorai et al. 2010 and Nath and Rahman 2012, where 2 or more larvae

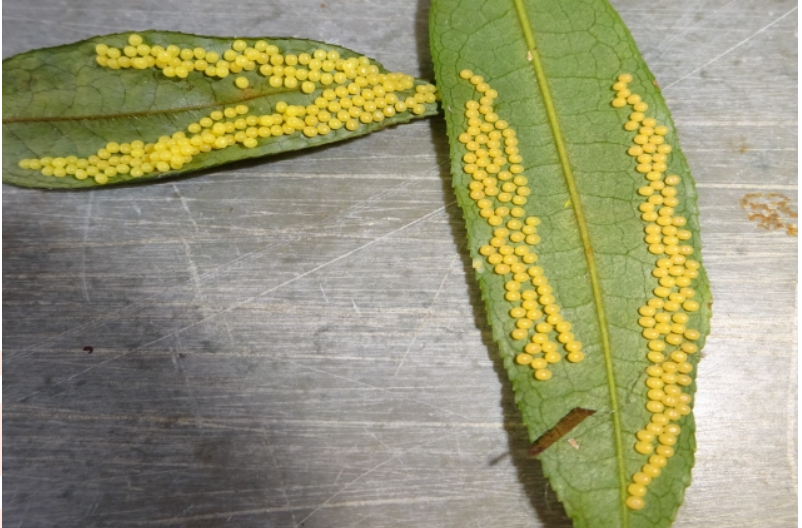

Fig. 7 : Egg laying by female adult of $A$. bipunctata on the underside of leaf of $E$. acuminata in rows.

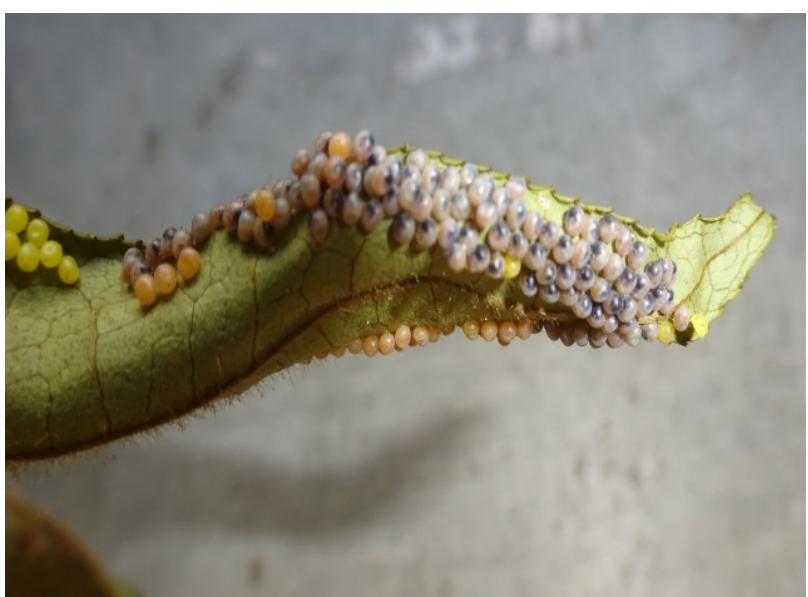

Fig. 9 : Before hatching egg of $A$. bipunctata turns to grey black in color.

pupated themselves in a single cocoon. Pupal period was recorded as $27.00 \pm 0.2$ days (mean $\pm S E M, n=50$ ) with $1.40 \pm 0.07$ days (mean $\pm S E M, n=50$ ) prepupal duration. Nearly less than 55 




Fig. 10 : Newly hatched larva of $A$. bipunctata remains on eggs.

per cent pupae were metamorphosed into adult. Ghorai et al. (2010) reported the relatively lesser metamorphosis of pupae of A. bipunctata into adult (nearly $53 \%$ ). Male emerged first but lived for shorter duration than female. This phenomenon was found as the general trend in A. bipunctata. Adult longevity for male and female was recorded as $11.20 \pm 0.1$ days (mean $\pm S E M, n=50$ ) and $13.80 \pm 0.1$ days (mean $\pm S E M, n=50$ ) respectively. Female moths were bigger in size and selected the nearest male for mating (end to end mating) (Fig. 6). Mated female moved towards the leaf margin for oviposition and preferred to lay eggs underside of $E$. acuminata leaf in rows during the scotophase and also during the photophase when the weather was cloudy (Fig.7). Lifetime fecundity of the female was recorded as $373.00 \pm 2.7$ eggs/female (mean \pm SEM, $n=50$ ) which was similar to the data in literature where it was reported that fecundity of female varies from 100 to 480 eggs/female, and usually depends on the generation of $A$. bipunctata (Ghorai et al., 2010). Eggs were oval in size and light green in color which later turned to reddish yellow (Fig.8). Mated female took 40-50 seconds to lay eggs on the leaf. Single female used more than one leaf to lay eggs in a row but conspecific females didn't lay eggs on the same leaf which confirm the presence of some oviposition deterrency associated with eggs. During oviposition, avoidance of preoccupied substrate by the
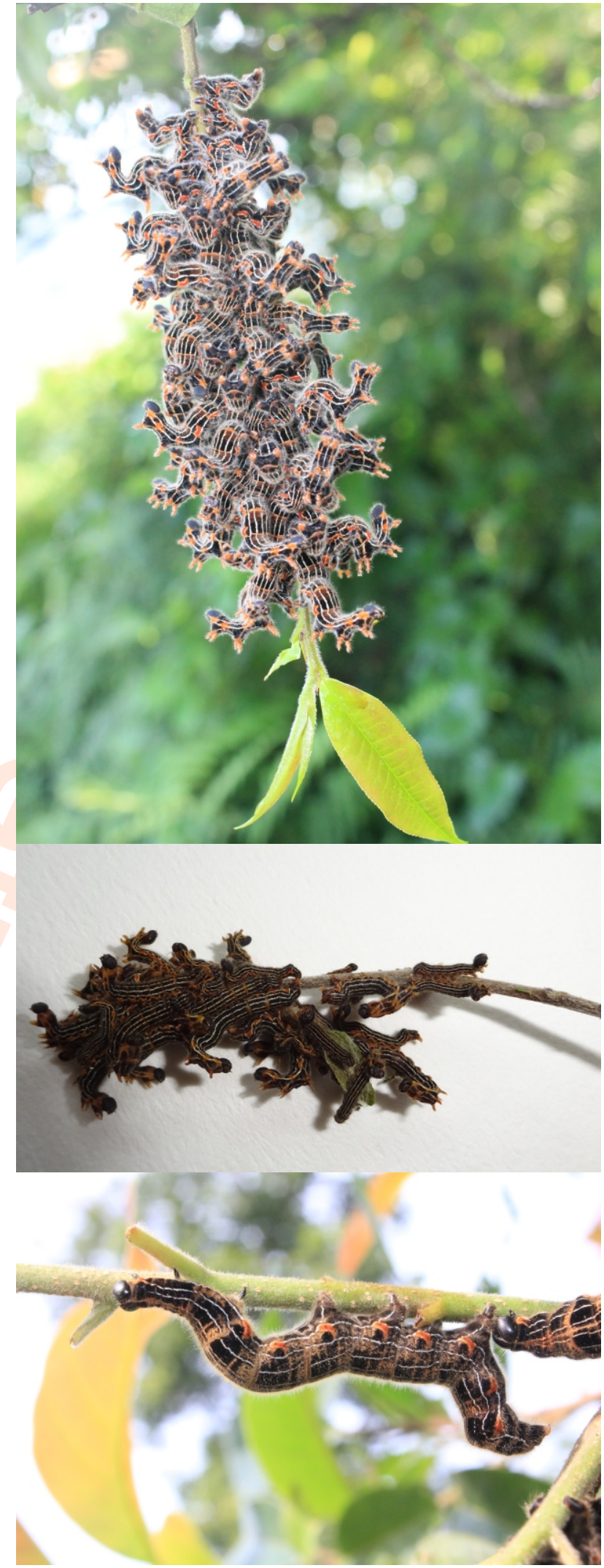

Fig. 11 : Caterpillar of $A$. bipunctata with grey to blackish body coloration, and yellow dorsal-intersegment stripes, devour the whole bunch of leaf. 
conspecific female was also confirmed by Ghorai et al. (2010). The incubation period of eggs was recorded as $3.40 \pm 0.1$ days (mean $\pm S E M, n=50$ ). Before hatching the eggs turned in to grey in color and then black (Fig.9). Nearly 20 per cent eggs did not show any change in color so never hatched hence hatching of eggs was recorded as $80 \pm 0.7$ per cent (mean $\pm S E M, n=50$ ). Newly hatched active larva remained on eggs for few minutes (Fig.10) before moving in search of food. Bunch of caterpillars first fed on leaf margin and then devoured the whole leaf (Fig.11). Total life cycle of $A$. bipunctata was found as $74.00 \pm 0.1$ days (mean \pm SEM, $\mathrm{n}=50$ ) in laboratory condition. At Jorhat, Assam during summer, pre-winter and winter condition A. bipunctata completed a generation within 56 days, 84 days and 132 days respectively on tea leaves (Andrews, 1931; Rustagi, 1995). In present study also, at ambient temperature under controlled condition life cycle was completed in short time period i.e., $74.00 \pm 0.1$ days.

Management of alternative hosts always remains a component in pest management programme. This finding will be useful information to the tea grower of Meghalaya to monitor the pest incidence on both alternative host plant and tea plantation for effective and timely management of this pest.

\section{Acknowledgments}

The authors are thankful to the Director, ICAR Research Complex for North Eastern Hill Region, Umiam for providing the required facilities during research work. We duly acknowledge the help of Dr P. R. Shashank, Scientist, Division of Entomology, Indian Agricultural Research Institute (IARI), New Delhi for identifying the moth species. Authors are also grateful to NICRA (National Innovations on Climate Resilient Agriculture) for the financial support.

\section{References}

Andrews, E.A.: Caterpillar pests of the tea plant, and of green manure plants and shade trees in use of tea estates. Q. J. Indian Tea Association, 19, 189-202 (1931).

Banerjee, B.: Arthropod accumulation on tea in young and old habitats. Ecol. Entomol., 8, 117-23 (1983).

Banerjee, B.: A strategy for the control of Andraca bipunctata Walker on tea. Crop Prot., 1, 115-119 (1982).

Chu, H.F. and L.Y. Wang: Fauna Sinica Insecta V, Lepidoptera: Bombycidae. Science Press, Beijing, p. 24 (1996).

Ghorai, N., S.K. Raut and A.K. Bhattacharyya: Behavioural ecology of a tea pest, Andraca bipunctata (Lepidoptera: Bombycidae), in the Sub-Himalayan climate of Darjeeling (India). Biological Letters, 47, 65-80 (2010).
Hazarika, L.K., K.C. Puzari and S. Wahab: Biological control of tea pests. In : Biocontrol Potential And Its Exploitation In Sustainable Agriculture (Eds.: R.K. Upadhyay, K.G. Mukerji and B.P. Chamola). New York: Kluwer Academic I Plenum Publishers, pp. 159-180 (2001).

Hazarika, L.K., M. Borthakur, K. Singh and S. Sannigrahi: Present status and future prospects of biological control of tea pests in North-East India. In: Proc. $32^{\text {nd }}$ Tocklai Conference, Tea Research Association Tocklai Experimental Station, Jorhat, pp. 169-177 (1994a).

Huxley, A., M. Griffiths and M. Levy: New RHS Dictionary of Gardening. Macmillan, London, ISBN 0-333-47494-5 (1992).

Kanjilal, U.N., P.C. Kanjilal, A. Das and R.N. De: Flora of Assam. Vol. I-IV, Government of Assam, Shillong (1934-1940).

Kumata, T.: A contribution to the knowledge of the Malayasian Lithocolletinae (Gracillariidae, Lepidoptera), with a revision of Indian Cameraria associated with Leguminosae. Insecta Matsumurana, 48, 1-85(1993).

Muraleedharan, N.: Pest control in Asia. In: Tea Cultivation to Consumption (Eds.: K.C. Wilson and M.N. Cliford), London, Chapman and Hall, pp.375-411 (1992).

Nath, M. and I. Rahman: Biology of bunch caterpillar, Andraca Bipunctata Walker- a major insect pest of tea in North-East India. Indian J. Entomol., 74,303-305 (2012).

Panigrahi, A.: Effect of relative humidity on hatching of eggs of the tea pest Andraca bipunctata Walker (Lepidoptera: Notodontidae). Indian Biol., 39, 9-11 (2007).

Rustagi, P.N.: Manual on Tea Culture. Tocklai Experimental Station, Tea Research Association, Jorhat, Assam, India (1995).

Saha, D. and A. Mukhopadhyay: Insecticide resistance mechanisms in three sucking insect pests of tea with reference to North-East India - an appraisal. Int. J. Trop. Insect. Sci., 33, 46-70 (2013).

SPSS.: Inc. SPSS for windows, Released version 16.0. Chicago, SPSS Inc. (2007).

Soni, R.P., M. Katoch, A. Kumar, R. Ladohiya and P. Verma: Tea: Production, composition, consumption and its potential an antioxidant and antimicrobial agent. Int. J. Food Ferment. Technol., 5, 95-106 (2015).

Subramanium, B.: Tea in India. New Delhi: $1^{\text {st }}$ Edn., Publications and Information Directorate, New Delhi and Wiley Eastern Ltd. (1995).

Wang, X., M. Wang, L.Y. Dai and V.V. Zolotuhin: A revised annotated and distributional checklist of Chinese Andraca (Lepidoptera, oberthuerinae) with description of a new subspecies. Fla. Entomol., 95, 552-560 (2012).

Wang, X., L. Zeng and M.Wang: The genus Andraca (Lepidoptera, Endromidae) in China with description of a new species. Zookey, 127, 29-42 (2011).

Wu, Z.Y., P.H. Raven and D. Hong: Flora of China. Science Press, Beijing, Missouri Botanical Garden Press, St. Louis (1994-2013). 